\title{
The first successful use of the Levitronix PediMag ventricular support device as a biventricular bridge to transplant in an infant
}

\author{
Rabin Gerrah, MD, Kevin Charette, CCP, and Jonathan M. Chen, MD, New York, NY
}

Continuous improvements in the outcomes for children undergoing heart transplant have increased the number of neonates and infants listed for transplant. The number of available donor organs remains static, however, increasing the need for bridging to transplant. Recent enthusiasm for mechanical ventricular assistance in this age group has disclosed significant challenges with respect to adequate anticoagulation and consequent thrombotic or bleeding complications during the course of device support. ${ }^{1-2}$ We report here the first successful use of the Levitronix PediMag ventricular assist device (Levitronix, LLC Waltham, Mass) both as biventricular support as a bridge to transplant, and also for extracorporeal membrane oxygenation (ECMO) after transplant. This circuit is particularly attractive because of its small priming volume, ease of use, ready availability, and flexibility of application. In this setting, we endorse the use of a limited circuit length, of heparin-coated tubing and connectors, and of a simplified circuit in an effort to reduce the likelihood of thrombotic events.

\section{CLINICAL SUMMARY}

A 51/2-month-old, 5.8-kg female infant was admitted to the pediatric intensive care unit at our institution with dilated cardiomyopathy. The patient was listed for heart transplant, and initially she was managed with high-dose inotropic support. Her cardiac history was remarkable for multiple ventricular septal defects, supraventricular arrhythmias, and severe biventricular dysfunction. In the setting of biventricular failure, deteriorating end-organ perfusion, and metabolic acidosis, and with no donor heart available, the decision was made to proceed with emergency mechanical support as a bridge to transplant.

A Levitronix PediMag blood pump was used for both right and left ventricular assistance. The procedure was

\footnotetext{
From the Division of Cardiothoracic Surgery, Department of Surgery, Columbia University College of Physicians and Surgeons, New York, NY, and the Department of Surgery, Weill Medical College of Cornell University, New York, NY.

Disclosures: Authors have nothing to disclose with regard to commercial support.

PediMag is manufactured by Levitronix, LLC Waltham, Mass.

Received for publication Jan 13, 2011; revisions received March 17, 2011; accepted for publication March 28, 2011; available ahead of print April 29, 2011.

Address for reprints: Rabin Gerrah, MD, Pediatric Cardiac Surgery Children's Hospital of New York, 3959 Broadway, Suite 2-273, New York, NY 10032 (E-mail: rg2533@columbia.edu).

J Thorac Cardiovasc Surg 2011;142:1282-3

$0022-5223 / \$ 36.00$

Copyright (c) 2011 by The American Association for Thoracic Surgery doi:10.1016/j.jtcvs.2011.03.026
}

performed without cardiopulmonary bypass and with biatrial cannulation with 18F DLP cannulas (Medtronic Inc, Minneapolis, Minn), coated, in the left atrium through the right lateral aspect and in the Waterston groove through concentric purse-string sutures and a 20F DLP cannula, coated, in the right atrium to $210 \mathrm{~F}$ Bio-Medicus cannulas (Medtronic) in the great arteries and 30 inches of inflow and outflow Smart-coated 1/4-inch tubing (Sorin Group USA, Inc, Arvada, Colo). Performing the procedure off pump allowed us to use a half dose of heparin and also made the procedure less invasive. Administration of apical cannulation and cardiopulmonary bypass would have increased the risk of bleeding. Alternatively, a separate approach to the left ventricular apex by way of a left anterior thoracotomy would have required a separate incision as well.

The procedure was uneventful, and the chest was left open for management of the postoperative bleeding. Biventricular assist flows were maintained at approximately 650 to $900 \mathrm{~mL} / \mathrm{min}$ with a pump speed of 3000 to $3700 \mathrm{rpm}$. Anticoagulation was managed with unfractionated heparin adjusted to maintain a partial thromboplastin time of 80 to 100 seconds.

The immediate postoperative course was complicated by significant hemorrhage, necessitating several mediastinal explorations. After 17 days of biventricular support, the patient underwent orthotopic heart transplant and explantation of the biventricular assist device. Despite an ischemic time of 2 hours and 49 minutes, severe primary graft failure developed, with minimal response to high-dose inotropic support. Subsequently, the child was supported for 8 days with ECMO that used the Levitronix PediMag pump with a Maquet QUADROX-iD oxygenator (Maquet Gmbh \& Co KG, Rastatt, Germany). This 1/4-inch Sorin Smart-coated circuit was connected to a 20F DLP right atrial cannula (noncoated) Yd with a 10F DLP left atrial vent, and the arterial cannula was a $10 \mathrm{~F}$ Bio-Medicus. Because of bleeding concerns, the first 12 hours of ECMO support were performed without adjunct heparin; thereafter, the partial thromboplastin time was again maintained between 60 and 90 seconds. Echocardiography demonstrated a gradual improvement in ventricular function as well as a left ventricular thrombus. Ultimately, after 8 days of ECMO support, the patient was weaned and decannulated. At this time, thrombus was evident in centrifugal head. Clinically, the patient showed signs of bilateral cerebrovascular accidents but with no seizure activity, and 
throughout the follow-up period the child has demonstrated evidence of ongoing neurologic improvement.

This represents the youngest reported patient to be supported successfully to transplant with the PediMag pump. In addition, the PediMag was later used as posttransplant ECMO support in combination with the QUADROX-iD oxygenator. When using $1 / 4-$ inch tubing connections with minimal length, the priming volume of the ECMO circuit is less than $160 \mathrm{~mL}$, and the cannulas are readily available and easy to implant. Thrombotic complications continue to plague mechanical assistance in this age group, highlighting the importance of ongoing vigilance for areas of turbulence or stasis while the patient is receiving device support. In light of this, we endorse the use of coated tubing, connectors, and cannulas, and we prefer to limit the complexity of the circuit where possible. Relative to our previous mechanical circulatory assist experience in children ${ }^{3}$ with the CentriMag (Thoratec Corporation, Pleasanton, Calif) at low flow, we have found the PediMag to be less prone to thrombus while being comparably easy to implant and use postoperatively.

\section{References}

1. Stiller B, Benk C, Schlensak C. Mechanical cardiovascular support in infants and children. Heart. 2011;97:596-602.

2. Brancaccio G, Amodeo A, Ricci Z, Morelli S, Gagliardi MG, Iacobelli R, et al Mechanical assist device as a bridge to heart transplantation in children less than 10 kilograms. Ann Thorac Surg. 2010;90:58-62.

3. Hirata Y, Charette K, Mosca RS, Quaegebeur JM, Chen JM. Pediatric application of the Thoratec CentriMag BiVAD as a bridge to heart transplantation. J Thorac Cardiovasc Surg. 2008;136:1386-7.

\title{
Robotic transthoracic esophagectomy in the prone position: Experience with 32 patients with esophageal cancer
}

\author{
Shailesh Padmakar Puntambekar, MS, Neeraj Rayate, MS, DNB, Sourabh Joshi, MS, and \\ Geetanjali Agarwal, MS, Pune, India
}

The first case description of thoracoscopic esophagectomy aided by the da Vinci robotic system (Intuitive Surgical, Inc, Sunnyvale, Calif) was published in 2004 by Kernstine and colleagues. ${ }^{1}$ We report here our singleinstitution experience of 32 robot-assisted esophagectomies with the da Vinci robot in which mobilization of the esophagus was done with the patient in the prone position.

\section{OPERATIVE TECHNIQUE}

The patient was placed in the prone position on an operative sandbag. The robotic cart was situated to the left side of the patient. The operative trocars for the robot (one 12$\mathrm{mm}$ port for the camera and two 8-mm ports for the arms) were placed (Figure 1). The first port was inserted 1 finger-breadth below and posterior to inferior angle of scapula in the 5th or 6th intercostal space. Two 8-mm trocars were positioned under direct thoracoscopic vision in a vertical line at a distance of $5 \mathrm{~cm}$ and in triangulation with the camera port in the third and eighth intercostal spaces, respectively. One $10-\mathrm{mm}$ port for the assistant was placed

From the Galaxy Care Laparoscopy Institute, Pune, Maharashtra, India.

Disclosures: Authors have nothing to disclose with regard to commercial support.

Received for publication Aug 26, 2010; revisions received March 18, 2011; accepted

for publication March 28, 2011; available ahead of print May 2, 2011.

Address for reprints: Shailesh Padmakar Puntambekar, MS, Galaxy Care Laparos-

copy Institute, Pune, Maharashtra 411004, India (E-mail: shase63@gmail.com).

J Thorac Cardiovasc Surg 2011;142:1283-4

0022-5223/\$36.00

Copyright (c) 2011 by The American Association for Thoracic Surgery

doi:10.1016/j.jtcvs.2011.03.028 between the left working port and the camera port. This was used for suction and clip application. Pneumoinsufflation was created at a pressure of $7 \mathrm{~mm} \mathrm{Hg}$.

With the patient in a prone position, the esophagus falls anteriorly out of its normal position, which creates natural tension and simplifies dissection. We used Maryland bipolar forceps in left arm and hot shears (scissors with monopolar current) in right arm of the robot. The procedure began with the incision of the visceral pleura between the esophagus

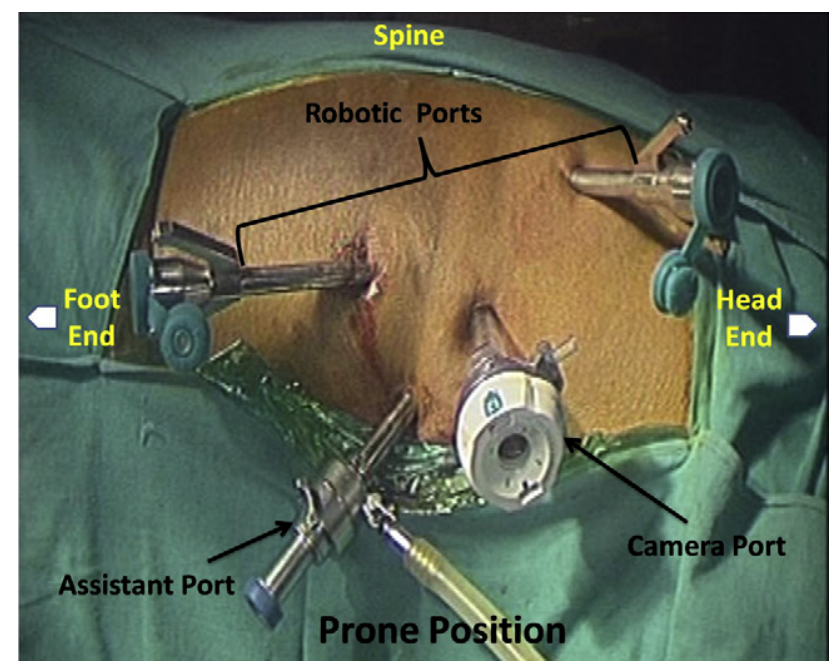

FIGURE 1. Instrumentation for transthoracic esophagectomy with the da Vinci robotic system (Intuitive Surgical, Inc, Sunnyvale, Calif). 